\title{
The Lodgepole Pine
}

By W. C. McCalla, Calgary, Alberta

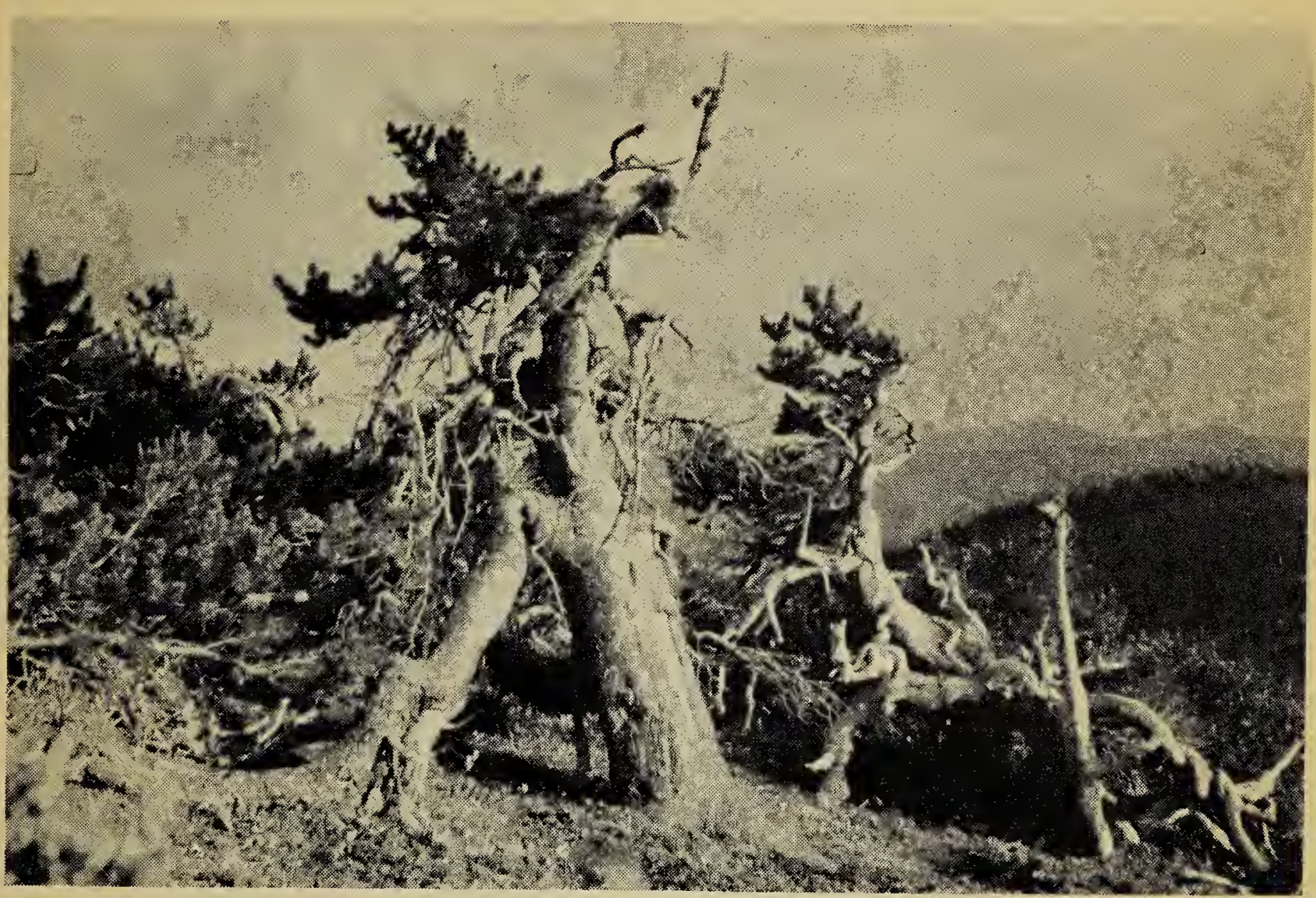

LODGEPOLE PINE ON CORNWALL HILLS, B.C.

Photo by W. C. McCalla.

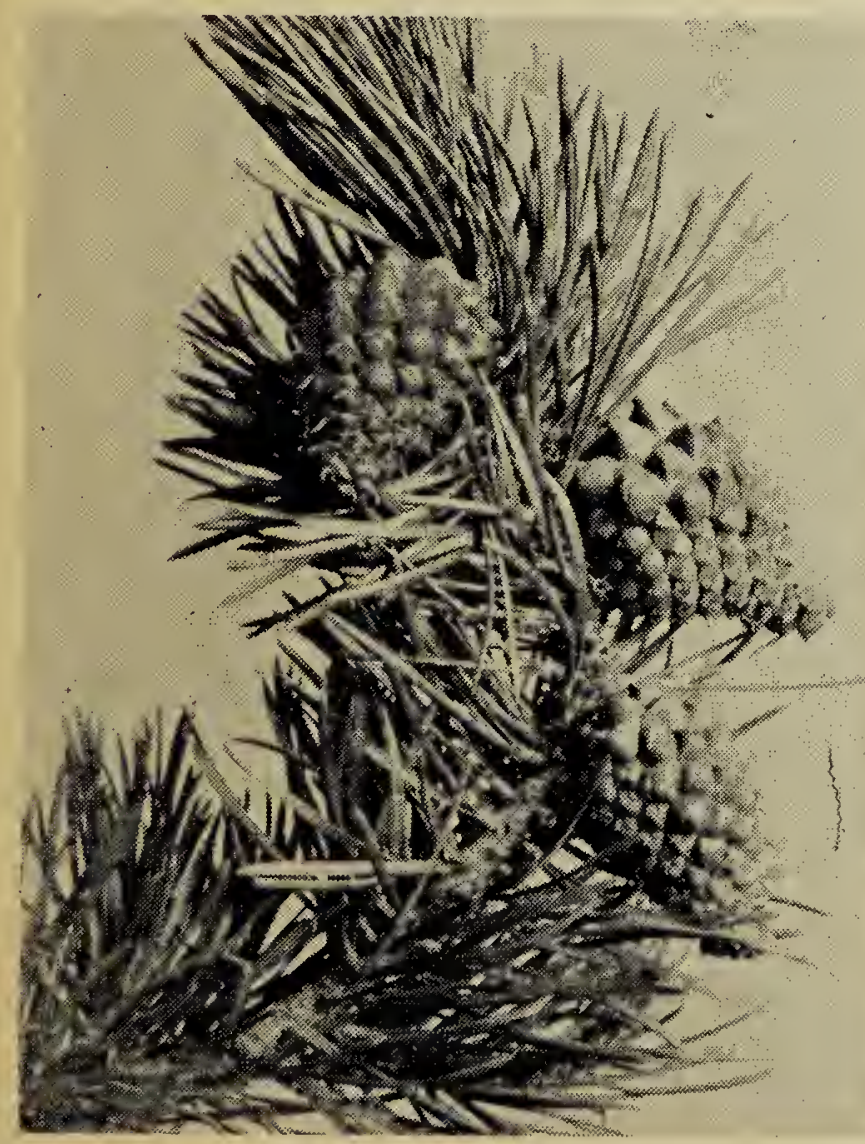

Photo by W. C. McCalla. LEAVES AND CONES OF LODGEPOLE PINE
The Lodgepcle Pine, Pinus contorta Dougl. var. Iatifolia Engelm., is a western pine. It is limited to the Cypress Hills in Saskatchewan but it is abundant in Alberta and British Columbia.

In deep, moist, well-drained soil it forms dense forests of tall, straight trees of almost uniform height and girth. On exposed rocky ridges, the trees are stunted, strangely bent and twisted as shown in the photograph.

These pictures were taken on the Cornwall Hills, near Ashcroft, B.C., at an elevation of 6,000 feet. I wondered about the age of these trees so a forestry man cut a dead tree of similar size. The annual rings showed that for 112 years these trees had been beaten by storm, by wind and by snow and ice, yet the leaves on the living branches were a healthy green, and the cones were about, normal in size and shape. 